\title{
Lung Protective Ventilation Improves Oxygenation and Shortens ICU Stay in Patients undergoing Minimally Invasive Cardiac Surgery
}

Hsi-Yin Lin, Cheng-Wei Lu, Tzu-Yu Lin

Far Eastern Memorial Hospital, New Taipei City, Taiwan

\section{Background and Goal of study}

Lung-protective ventilation with low tidal volumes, high positive end-expiratory pressure, and lung recruitment has been demonstrated to improve patients' outcome in various kinds of surgery. However, its role in minimally invasive cardiac surgery has never been investigated. The aim of this study was to determine the impact of lung-protective ventilation on patients' outcome in minimally invasive cardiac surgery.

\section{Materials and Methods}

Lung protective ventilation was implemented strictly since June 1, 2016 in our institution. Therefore, we retrospectively examined the clinical records of patients receiving minimally invasive cardiac surgery form April to July 2016. The intraoperative $\mathrm{PaO}_{2} / \mathrm{FiO}_{2}$ ratio (baseline, immediately after the weaning of cardiopulmonary bypass, and at the end of surgery) and postoperative parameters including length of ICU stay, length of hospital stay, and postoperative lactate level were compared between the group receiving lung-protective ventilation since June $(n=18)$ and the group before June $(n=16)$. Statistical analysis was performed using SPSS v.22 (IBM Corp., USA). The Kolgomorov-Smirnov with Lilliefor correction test was performed for variable normality and Levene's test was used for homogeneity of variances. When the homogeneity hypothesis was not rejected, the paired $t$ test or one-way ANOVA was applied where appropriate.

\section{Results and Discussion}

\begin{tabular}{|c|c|c|c|}
\hline (Mean $\pm S D)$ & $\begin{array}{l}\text { Protective } \\
\quad(\mathrm{N}=18)\end{array}$ & $\begin{array}{l}\text { Conventional } \\
\quad(\mathrm{N}=16)\end{array}$ & $\begin{array}{c}\text { Total case } \\
(\mathrm{N}=34)\end{array}$ \\
\hline Pre-operation & $401.5 \pm 65.3$ & $413.6 \pm 83.4$ & $407.8 \pm 74.8$ \\
\hline Post-bypass & $299.5 \pm 163.2$ & $321.7 \pm 175.9$ & $311.0 \pm 168.6$ \\
\hline \multirow[t]{2}{*}{ End of operation } & $362.5 \pm 147.9$ & $353.4 \pm 134.5$ & $357.8 \pm 139.8$ \\
\hline & -1.05 & -0.823 & -1.7 \\
\hline$P$ value & $k 0.01$ & 0.418 & 0.096 \\
\hline
\end{tabular}

\begin{tabular}{|c|c|c|c|c|}
\hline \multicolumn{5}{|c|}{ Table2: Outcome } \\
\hline & $\begin{array}{l}\text { Protective } \\
\text { Mean( } \pm \text { SD) }\end{array}$ & $\begin{array}{l}\text { Conventione } \\
\text { Mean( } \pm S D)\end{array}$ & $\begin{array}{l}\text { RR } \\
(95 \% \mathrm{Cl})\end{array}$ & $\begin{array}{l}\mathrm{P} \text { - } \\
\text { value }\end{array}$ \\
\hline LOS*(ICU) & $3.4(0.9)$ & $4.6(2.0)$ & $\begin{array}{l}\mathbf{5 . 0 1} \\
(3.37-4.56)\end{array}$ & 0.03 \\
\hline $\begin{array}{l}\text { LOS* } \\
\text { (hospital) }\end{array}$ & $9.4(3.2)$ & $14.5(6.4)$ & $\begin{array}{l}8.29 \\
(9.71-13.71)\end{array}$ & 0.07 \\
\hline$\triangle$ Lactate & $2.8(1.9)$ & $2.8(1.7)$ & $\begin{array}{l}0.002 \\
(2.10-3.43)\end{array}$ & 0.92 \\
\hline
\end{tabular}

\section{Conclusion}

Our results suggest lung protective ventilation with recruitment maneuver may improve oxygenation and reduce the length of ICU stay in patients receiving minimally invasive cardiac surgery. 